\title{
Effect of the natural compound trans-resveratrol on human MCM4 gene transcription
}

\author{
FUMIAKI UCHIUMI $^{1}$, CHIHIRO KATSUDA ${ }^{1}$, MOTOHIRO AKUI $^{1}$, MONAMI KUSAKA $^{1}$, \\ MARIE TANAKA ${ }^{1}$, MASASHI ASAI ${ }^{1}$ and SEI-ICHI TANUMA ${ }^{2,3}$
}

\begin{abstract}
Departments of ${ }^{1}$ Gene Regulation and ${ }^{2}$ Biochemistry, Faculty of Pharmaceutical Sciences, Tokyo University of Science;
${ }^{3}$ Genomic Medicinal Science, Research Institute of Science and Technology, Tokyo University of Science,

Noda-shi, Chiba-ken 278-8510, Japan
\end{abstract}

Received July 12, 2019; Accepted March 11, 2020

DOI: $10.3892 /$ or.2020.7598

\begin{abstract}
Resveratrol (Rsv) is a natural compound contained in red wine and grape skins that has various beneficial effects for organisms such as lengthening of their life span. Rsv induces expression of the human TP53 and HELB genes, which are involved in the regulation of DNA maintenance. In the present study, a luciferase expression vector containing 309 bp of the 5' upstream end of the human MCM4 gene was transfected into HeLa S3 cells. A luciferase assay revealed that Rsv treatment increased the minichromosome maintenance 4 (MCM4) gene promoter activity by GC-box and GGAA (TTCC) motifs. Electro phoretic mobility shift assay revealed that the specific binding factor (complex) contains PU.1 (SPI1). Quantitative reverse transcription-polymerase chain reaction analysis indicated that MCM4 gene expression was transiently induced by Rsv. Moreover, western blotting revealed that the SP1/PU.1 ratio markedly increased after Rsv treatment, indicating that a balance or profile of these transcription factors may control Rsv-inducible initiation of transcription. These observations indicated that the beneficial effects of Rsv can be attributed to induction of the chromosomal DNA maintenance factor encoding gene expression.
\end{abstract}

Correspondence to: Dr Fumiaki Uchiumi, Department of Gene Regulation, Faculty of Pharmaceutical Sciences, Tokyo University of Science, 2641 Yamazaki, Noda-shi, Chiba-ken 278-8510, Japan E-mail: uchiumi@rs.noda.tus.ac.jp

Abbreviations: CMG complex, CDC45-MCM-GINS complex; $\mathrm{C}_{\mathrm{T}}$, threshold cycle; DIG, digoxigenin; DMEM, Dulbecco's modified Eagle's medium; EMSA, electric mobility shift assay; FBS, fetal bovine serum; Luc, luciferase; MCM, minichromosome maintenance; PCR, polymerase chain reaction; Rsv, trans-resveratrol; RT-PCR, reverse transcription-polymerase chain reaction; RT-qPCR, quantitative reverse transcription-polymerase chain reaction; TSS, transcription start site

Key words: ETS, GGAA, MCM4, resveratrol, transcription

\section{Introduction}

DNA replication in mammalian cells is accurately controlled by a number of protein factors. The initiation of DNA replication that takes place at replication origins is coordinately controlled by multiple proteins, including ORC, CDC6, CDC45, CDKs, CTD1, GINS, and MCM2-7 helicase complex $(1,2)$. Loading of the replicative MCM2-7 helicase complex on the replication initiation sites is considered to be of primary importance (3). Recently, a molecular model for the formation of stable double hexamers at replication origins has been proposed (4). The replicative helicase is not only required for DNA unwinding but also for tethering DNA primase to synthesize short RNA primers for DNA chain elongation on the lagging strand (5). In yeast cells, among this helicase complex, minichromosome maintenance 4 (Mcm4), co-operating with Sld3 and Dbf4, plays an essential role in the regulation of origin firing and replication fork progression (6). A mutation in the MCM4 gene has been reported in mammary adenocarcinomas in mice (7). The G486D mutation in the MCM4 protein affects formation of the MCM2/4/6/7 complex, and that could cause the generation of human cancer (8). Moreover, whole genome sequencing of human thymic adenocarcinoma revealed that a complex chromosomal rearrangement in chromosome 8 caused fusion of the MCM4 and SNTB1 genes (9). These lines of evidence indicate that dysregulation of the MCM4 function may be deleterious for control of the initiation of DNA replication.

Recent studies on molecular structure revealed that the MCM2-7 hexamer physically interacts with ORC-Cdc6 and Ctd1 proteins to be loaded onto the replication initiation site in yeast $(10,11)$. Moreover, it has been reported that phosphorylation and SUMOylation of MCM4 regulate the accurate initiation of replication (12-14). Although the structure and functions of MCM4 have been studied, its mechanism of gene expression has not been revealed. Surveillance of the human genomic DNA database indicated that the MCM4 gene is head-head bound with the protein kinase, DNA-activated, catalytic subunit (PRKDC) gene, which encodes DNA-PKcs (15). In the present study, a luciferase (Luc) expression plasmid containing 309 bp of the 5'-upstream end of the human MCM4 gene was constructed. The transfection and Luc reporter assay revealed that the 309-bp fragment functioned as a promoter 
and responded to trans-resveratrol (Rsv) both in HeLa S3 and HL-60 cells. A natural polyphenolic compound, Rsv, which is known to stimulate $\mathrm{NAD}^{+}$-dependent deacetylase sirtuin and lengthen the lifespan of model animals, upregulates the expression of the DNA repair-associated genes (16). For example, expression of the TP53 and HELB genes, which encode tumor suppressor p53 (17) and RecD-like DNA helicase HDHB (18), respectively, are induced by Rsv in HeLa S3 cells, and notably, a duplicated GGAA motif is present in the 5' upstream end of these two genes $(19,20)$. In contrast, in the human TERT and $W R N$ gene promoter regions, a GC-box has been identified as a common Rsv-responsive element (21).

In the present study, deletion and point mutations on the GGAA motif and the GC-box markedly decreased MCM4 promoter activity and its response to Rsv both in HeLa S3 and HL-60 cells. Reverse transcription-quantitative polymerase chain reaction (RT-qPCR) and western blotting revealed that the MCM4 gene transcripts and its encoding protein accumulated in HeLa S3 cells. Electrophoretic mobility shift assay (EMSA) with various antibodies revealed that PU.1 (SPI1) and Sp1 bind to the Rsv-responsive sequence. Collectively, the findings indicated that the GGAA motif and the GC-box are essential for the control of MCM4 gene expression in response to Rsv treatment of HeLa S3 cells.

\section{Materials and methods}

Materials. trans-Resveratrol (Rsv) (cat. no. CAS501-36-0) was purchased from Cayman Chemical $(19,20)$.

Cells and cell culture. Human cervical carcinoma (HeLa S3) cells $(19,20)$ and human promyelotic leukemia (HL-60) cells (22) were grown in Dulbecco's modified Eagle's medium (DMEM) and RPMI-1640 medium (Nacalai Tesque, Inc.), respectively, supplemented with $10 \%$ fetal bovine serum (FBS) (Biosera) and penicillin-streptomycin at $37^{\circ} \mathrm{C}$ in a humidified atmosphere with $5 \% \mathrm{CO}_{2}$.

Construction of Luc reporter plasmids. The Luc reporter plasmids, carrying $309 \mathrm{bp}$, which contains both transcription start sites (TSSs) of the human MCM4 and PRKDC genes, were constructed by the slight modification of a previously described procedure (19-22). Briefly, polymerase chain reaction (PCR) was performed with the hPRKDC-0028/AhPRKDC-0336 primer pair (Table I) and genomic DNAs that were extracted from HeLa S3 cells. The amplified DNA fragment was treated with HindIII and then ligated into the multi-cloning site of pGL4.10[luc2] (Promega Corporation). The resultant plasmids, containing the 309-bp fragment in correct and reverse orientations, were named pGL4-MCM4-309 and pGL4-PRKDC-309, respectively. Similarly, other Luc reporter plasmids were constructed by ligating a PCR-amplified DNA fragment into the KpnI/XhoI site of pGL4.10[luc2]. The sense and anti-sense primers used for the amplification of the DNA fragments are presented in Table I. Nucleotide sequences were confirmed by a DNA sequencing service (FASMAC; Greiner Japan, Inc.) with primers Rv (TAG CAAAATAGGCTGTCCCC) and GL (CTTTATGTTTTT GGCGTCTTCC). The Luc reporter plasmids pGL4-PIF1, pGL4-TP53-551, pGL4-RB1, and pGL4-CDKN1A (pGL4-p21) were constructed as previously described $(19,22,23)$.
Transcription factor binding sequence analysis. The nucleotide sequence of the cloned 309-bp DNA fragment was subjected to analysis of human transcription factor binding elements by JASPAR 2016 (http://jaspar2016.genereg.net/).

Transient transfection and Luc assay. Luc reporter plasmids were transfected into HeLa S3 or HL-60 cells by the DEAE-dextran method in 96-well plates (24), and after $24 \mathrm{~h}$ of transfection, the culture medium was changed to Rsv $(20 \mu \mathrm{M})$ containing DMEM or RPMI-1640 medium with 10\% FBS, respectively. After a further $24 \mathrm{~h}$ of incubation, cells were collected and lysed with $100 \mu \mathrm{l}$ of $1 \mathrm{X}$ cell culture lysis reagent, containing $25 \mathrm{mM}$ Tris-phosphate (pH 7.8), 2 mM DTT, 2 mM 1,2-diaminocyclohexane-N,N,N',N',-tetraacetic acid, $10 \%$ glycerol, and $1 \%$ Triton $\mathrm{X}-100$ and then mixed and centrifuged at $12,000 \mathrm{x}$ for $5 \mathrm{sec}$. The supernatant was stored at $-80^{\circ} \mathrm{C}$. The Luc assay was performed with a Luciferase assay system (Promega Corporation), and relative Luc activities were calculated as previously described (20,22-25).

Western blot analysis. Cells were collected after Rsv-treatment. They were lysed in a RIPA buffer [20 mM Tris- $\mathrm{HCl}$ (pH 7.4), $0.1 \%$ SDS, $1 \%$ Triton $\mathrm{X}-100$, and $1 \%$ sodium deoxychlate]. The amount of Protein amount was analyzed with a protein assay kit (BioRad Laboratories, Inc.) according to the manufacturer's protocol. After SDS-PAGE (15\% acrylamide) (15 to $25 \mu \mathrm{g}$ proteins/lane) and blotting onto a PVDF (Immobilon-P) membrane as previously described $(19,20)$, Western blot analysis was carried out with antibodies against MCM4 (cat. no. sc-48407; Santa Cruz Biotechnology, Inc.), and $\beta$-actin (cat. no. A5441; Sigma-Aldrich; Merck KGaA) $(1: 1,000)$ at $20^{\circ} \mathrm{C}$ for $1 \mathrm{~h}$, followed by the incubation with horseradish peroxidase-conjugated anti-rabbit (cat. no. A0545) or anti-mouse IgG (cat. no. A9917) secondary antibodies (Sigma-Aldrich; Merck KGaA) $(1: 10,000)$ at $20^{\circ} \mathrm{C}$ for $1 \mathrm{~h}$ in a Blocking reagent TBS containing $0.05 \%$ Tween 20 and $0.5 \%$ casein. Signal intensities were detected with ImmunoStar LD (FUJIFILM Wako Pure Chemical Corporation) and quantified with a ChemiDoc image analysis system and ImageLab 6.0 software (BioRad Laboratories, Inc.).

Reverse transcription-quantitative polymerase chain reaction $(R T-q P C R)$. First-strand cDNAs were synthesized with ReverTra Ace (Toyobo Life Science), random primers (Takara Bio, Inc.), and total RNAs extracted from HeLa S3 cells. Real-time PCR analysis was carried out using a Mx3000P Real-Time qPCR System (Stratagene; Agilent Technologies, Inc.) (19,20). For PCR amplification, cDNAs were amplified by Thunderbird Realtime PCR Master Mix (Toyobo Life Science) and $0.3 \mu \mathrm{M}$ of each primer pair. The primer pairs for amplifying the human MCM4 and GAPDH transcripts were hMCM4-2097: AGG ACTACATTGCCTACGCG/AhMCM4-2216: AAACCATTC CCCGGCTACTG and hGAPDH556/hGAPDH642 $(19,20)$, respectively. Amplification was carried out initially for $1 \mathrm{~min}$ at $95^{\circ} \mathrm{C}$, followed by 40 cycles at $95^{\circ} \mathrm{C}(15 \mathrm{sec})$ and $58^{\circ} \mathrm{C}(30 \mathrm{sec})$. Quantitative PCR analysis for each sample was carried out in triplicate. Relative gene expression values were obtained by normalizing $\mathrm{C}_{\mathrm{q}}$ (quantification cycle) values of target genes in comparison with $\mathrm{C}_{\mathrm{q}}$ values of the GAPDH gene using the $\Delta \Delta \mathrm{C}_{\mathrm{q}}$ method (26). 
Table I. Primer pairs used for amplifying 5' upstream regions of the human MCM4 gene.

\begin{tabular}{|c|c|c|}
\hline Luc plasmid & Primer & Sequence (5' to $\left.3^{\prime}\right)$ \\
\hline \multirow[t]{2}{*}{ pGL4-MCM4-309 } & AhPRKDC-0028 & ATTAAGCTTGATGACCGGCCAGGGCAGCAC \\
\hline & hPRKDC-0336 & GGGAAGCTTAGCCACCCAAACTACCTCCGC \\
\hline \multirow[t]{2}{*}{ pGL4-MCM4-d1 } & hMCM4-0088 & ATTGGTACCCAGCAGGGAGCAACGCACACC \\
\hline & AhMCM4-0336 & ATTGGTACCCAGCAGGGAGCAACGCACACC \\
\hline \multirow[t]{2}{*}{ pGL4-MCM4-d2 } & hMCM4-0159 & ATTGGTACCTCGGCCCGGACCCGGAAATGC \\
\hline & AhMCM4-0336 & ACGCTCGAGTAGCCACCCAAACTACCTCCG \\
\hline \multirow[t]{2}{*}{ pGL4-MCM4-d3 } & hMCM4-0217 & ATTGGTACCAGGAACTTTCCCGGGGACCCC \\
\hline & AhMCM4-0336 & ACGCTCGAGTAGCCACCCAAACTACCTCCG \\
\hline \multirow[t]{2}{*}{ pGL4-MCM4-d4 } & hMCM4-0269 & ATGGGTACCGCGCCTCTTTGGCCCGAATCA \\
\hline & AhMCM4-0336 & ACGCTCGAGTAGCCACCCAAACTACCTCCG \\
\hline \multirow[t]{2}{*}{ pGL4-MCM4-d5 } & hMCM4-0028 & ATTGGTACCTTGATGACCGGCCAGGGCAGC \\
\hline & AhMCM4-0181 & ATTCTCGAGGCATTTCCGGGTCCGGGCCGA \\
\hline \multirow[t]{2}{*}{ pGL4-MCM4-d6 } & hMCM4-0028 & ATTGGTACCTTGATGACCGGCCAGGGCAGC \\
\hline & AhMCM4-0153 & ATTCTCGAGCACGCGCGGGAGCGGGACTCG \\
\hline \multirow[t]{2}{*}{ pGL4-MCM4-d7WT } & hMCM4-0159 & ATTGGTACCTCGGCCCGGACCCGGAAATGC \\
\hline & AhMCM4-0204 & AATCTCGAGCAGCCCCGCCTCCGCGCGTAGGGGCA \\
\hline \multirow[t]{2}{*}{ pGL4-MCM4-d7M1 } & hmMCM4-0159 & ATTGGTACCTCGGCCCGGACCCTTAAATGC \\
\hline & AhMCM4-0204 & AATCTCGAGCAGCCCCGCCTCCGCGCGTAGGGGCA \\
\hline \multirow[t]{2}{*}{ pGL4-MCM4-d7M2 } & hMCM4-0159 & ATTGGTACCTCGGCCCGGACCCGGAAATGC \\
\hline & AhmMCM4-0204 & AATCTCGAGCAGCACAGCATCCGCGCGTAGGGGCA \\
\hline \multirow[t]{2}{*}{ pGL4-MCM4-d7MM } & hmMCM4-0159 & ATTGGTACCTCGGCCCGGACCCTTAAATGC \\
\hline & AhmMCM4-0204 & AATCTCGAGCAGCACAGCATCCGCGCGTAGGGGCA \\
\hline
\end{tabular}

Shaded nucleotides indicate mutations that disrupt the c-ETS and GC-box consensus sequence motifs. MCM4, minichromosome maintenance 4.

EMSA. Nuclear extracts were prepared from either mock- or Rsv (20 $\mu \mathrm{M})$-treated cells as previously described (27). The double-stranded DNA probes d7WT, d7M1, d7M2, and $\mathrm{d} 7 \mathrm{MM}$ were obtained by annealing and treating primer pairs hMCM4-0159/AhMCM4-0204, hmMCM40159/AhMCM4-0204, hMCM4-0159/AhmMCM4-0204, and hmMCM4-0159/AhmMCM4-0204, respectively, with T4 polymerase (Table II). Double-stranded d7WT probe (approximately $0.1 \mathrm{ng}$ ) was labeled with digoxigenin (DIG) (Roche Applied Science), and binding reactions were carried out in a buffer containing $0.2 \mathrm{mM}$ EDTA, 20\% glycerol, $20 \mathrm{mM}$ Hepes-KOH (pH 7.9), $100 \mathrm{mM} \mathrm{KCl,} 1 \mathrm{mM}$ DTT, $1 \mathrm{mM}$ PMSF, $50 \mathrm{ng} / \mu \mathrm{l}$ of poly (dI-dC), and $5 \mathrm{ng} / \mu \mathrm{l}$ of poly-L-Lysine at $20^{\circ} \mathrm{C}$ for $20 \mathrm{~min}(27)$. The resulting reaction mixture was separated by native TBE-PAGE and transferred to a nylon membrane (PALL Corporation) in 0.5X TBE buffer and UV cross-linked with a transilluminator. Detection of labeled DNAs was performed with an alkaline phosphatase-conjugated anti-DIG antibody and CSPD ECL substrate (Roche Applied Science). Chemiluminescence was detected by a ChemiDoc image analysis system (BioRad Laboratories, Inc.). For competition EMSAs (28), a molar excess of unlabeled competitor probe was included in the binding reaction, as indicated in the figure legends. For EMSA supershift analysis, antibodies ( $1 \mu \mathrm{l})$ anti-PU.1, anti-ETS1, anti-NF- $\mathrm{BB}(\mathrm{p} 50)$, anti-STAT4, anti-IDH1, and anti-Sp1 (cat. nos. sc-22805, sc-111, sc-8414, sc-485, sc-49996, and sc-59, respectively;
Santa Cruz Biotechnology, Inc.), anti-ELK1 (cat. no. E3401; Sigma-Aldrich; Merck KGaA), anti-STAT1 (cat. no. 06-501; EMD Millipore), and anti-KLF4 (cat. no. GTX101508; GeneTex, Inc.) were added to the reaction mixture, containing nuclear proteins, poly (dI-dC), and poly-L-Lysine, then incubated at $20^{\circ} \mathrm{C}$ for $20 \mathrm{~min}$. Then, DIG-labeled probe was added to start the binding reaction.

Statistical analysis. Standard deviations (SD) for each data were calculated and results are presented as the means \pm SD from three independent experiments. Statistical analysis for data in Figs. 1 and 3 was performed with the Student's t-test $\left({ }^{*} \mathrm{P}<0.05\right.$ and ${ }^{* *} \mathrm{P}<0.01$, as indicated in the figures and legends, were considered to indicate statistically significant differences).

\section{Results}

Isolation and characterization of the human MCM4/PRKDC bi-directional promoter region. It has been revealed that GGAA duplex-containing human DNA repair-associated gene promoters, including the $H E L B$ promoter, respond to Rsv, which upregulates the NAD ${ }^{+}$NADPH ratio in HeLa S3 cells (29). HELB associates with CDC45 that interacts with MCM helicase to construct the CMG (CDC45-MCM-GINS) complex. On the basis of this background, it was hypothesized that $M C M$ promoter would respond to Rsv in concert with 
Table II. The double-stranded oligonucleotides used for EMSA.

\begin{tabular}{ll}
\hline Name & Sequence \\
\hline d7WT & 5'-attggtacCTCGGCCCGGACCCGGAAATGCCCCTACGCGCGGAGGCGGGGCTGCtcgagatt-3' \\
& 3'-taacCatgGAGCCGGGCCTGGGCCTTACGGGGATGCGCGCCTCCGCCCGACGagctctaa-5' \\
d7M1 & 5'-attggtacCTCGGCCCGGACCCTTAAATGCCCCTACGCGCGGAGGCGGGGCTGCtcgagatt-3' \\
& 3'-taacCatgGAGCCGGGCTGGGAATTTACGGGGATGCGCGCCTCCGCCCGACGagctctaa-5' \\
d7M2 & 5'-attggtacCTCGGCCCGGACCCGGAAATGCCCCTACGCGCGGATGCTGTGCTGCtcgagatt-3' \\
& 3'-taacCatgGAGCCGGGCTGGGCTTTACGGGGATGCGCGCCTACGACACGACGagctctaa-5' \\
d7MM & 5'-attggtacCTCGGCCCGGACCCTTAAATGCCCCTACGCGCGGATGCTGTGCTGCtcgagatt-3' \\
& 3'-taacCatgGAGCCGGCCTGGGATTTACGGGGATGCGCGCTACGACACGACGagctctaa-5'
\end{tabular}

Bold characters in d7M1, d7M2, and d7MM indicate mutations, which are the same as those introduced in the Luc expression plasmids, pGL4-MCM4-d7M1, pGL4-MCM4-d7M2 and pGL4-MCM4-d7MM, respectively. Lower-case letters indicate the tag sequences containing $K p n \mathrm{I}$ and $\mathrm{XhoI}$ restriction enzyme recognition sites.

the $H E L B$ promoter. First, the 309-bp fragment of the bi-directional MCM4/PRKDC promoter region (30) was amplified and isolated by PCR. Sequence analysis revealed that the pGL4-MCM4-309 and pGL4-PRKDC-309 plasmids contain a nucleotide identical to NCBI Sequence IDs NC_018919.2 (nucleotide from 48924950 to 48925258 ) and NC_000008.11 (nucleotide from 47960028 to 47960336 ) and that it covers the sequence of the most upstream 5 ' end of the cDNA (Sequence IDs: NM_005914.3 and NM_182746.2 for the variants 1 and 2 of $M C M 4$, respectively; GENE ID, MCM4: 4173). This 309-bp region also contains a 5' upstream end of variants 1 and 2 of the PRDKC mRNA (Sequence ID: NM_006904.6 and NM_001081640.1, respectively; GENE ID, PRKDC: 5591) in a reverse orientation to that of the MCM4 gene. The TSS was tentatively set as +1 at the most upstream 5' end of the MCM4 transcripts shown in the human genomic DNA database. The JASPAR 2016 database program (http://jaspar2016.genereg.net/) indicated that the characteristic recognition sequences of several known transcription factors are contained (Fig. 1A). Although no evident sequences similar to the TATA or CCAAT boxes were found, putative binding sites for GATA2 (-174 to -171), BRCA1 (-106 to -100$)$, YY1 (-81 to -76$)$, ERG1 (-68 to -55$)$, E2F1 (-63 to -53$)$, NRF1 (-57 to -47$)$, ELF1 (-36 to -24$)$, ELK1 $(-35$ to -26$)$, ETS1 (-31 to -26$),$ Sp2 $(-16$ to +21$)$, SPI1 $(+16$ to $+21,+39$ to +44$), \mathrm{NF}-\kappa \mathrm{B}(+18$ to +27$), \mathrm{Spl}(+38$ to +57$)$, FOXC1 $(+50$ to +57$)$, NFIC (+68 to +73$),$ FOXC1 $(+73$ to +84$)$, MZF1 (+77 to +82$)$, and THAP1 $(+87$ to +95$)$ were contained in the 309-bp region. To examine whether the isolated DNA fragment contains functional promoter activity, Luc reporter plasmids pGL4-PRKDC-309 and pGL4-MCM4-309 were transiently transfected into HeLa S3 cells. The relative Luc activities of the pGL4-PRKDC-309- (Fig. 1B, left panel) and pGL4-MCM4-309-transfected cells (Fig. 1B, right panel) increased after the addition of Rsv to the cell culture. It has been observed that HeLa S3 cells are not killed or not induced to proliferate with $20 \mu \mathrm{M}$ of the Rsv treatment, and the activation of the human TP53 gene promoter was most prominent with the concentration (20). Based on the observation, the experimental condition for HeLa S3 cells was set as $20 \mu \mathrm{M}$. The upregulation of Luc activities in response to Rsv was significantly greater in the pGL4-MCM4-309-transfected cells than in the pGL4-PRKDC-309-transfected cells. The MCM4 gene/protein expression and promoter activity was further examined. In this experimental setting, the duplicated GGAA motif containing promoters of the human $R B 1$ and $C D K N 1 A$ ( $p 21)$ genes responded positively to Rsv (Fig. 1C).

Effects of Rsv on MCM4 gene expression and its protein amount in HeLa S3 cells. Next, total RNAs were extracted from cells after adding Rsv to the culture medium, and RT-qPCR was carried out (Fig. 2A). Since apparent up-/down-regulation of the expression of the GAPDH in HeLa S3 cells in response to trans-resveratrol (Rsv) (20) has not been observed, this gene was used as a control for the RT-qPCR experiment. The relative gene expression of MCM4 compared with that of GAPDH began to increase at $2 \mathrm{~h}$ after Rsv treatment and then reached a plateau. Western blot analysis revealed that the amount of MCM4 protein peaked at $24 \mathrm{~h}$ after the treatment (Fig. 2B). The slight decrease at $32 \mathrm{~h}$ may have been caused by degradation of the MCM4 protein, non-coding regulatory RNAs, or another post-transcriptional regulation in HeLa S3 cells. However, after a further $12 \mathrm{~h}$ of incubation it increased again.

Effect of Rsv on the MCM4 promoter activity. To narrow the Rsv-responsive sequence, deletion from the $5^{\prime}$ and $3^{\prime}$ ends of the 309-bp MCM4 promoter region was introduced into the pGL4-MCM4-309 plasmid (Fig. 3A). The induction by Rsv was observed in the HeLa S3 and HL-60 cells transfected with pGL4-MCM4-d1 and d2, but no apparent Luc activity was observed in the cells transfected with pGL4-MCM4-d3, $-\mathrm{d} 4$, and -d6. Comparison of the Luc activities from the cells transfected with pGL4-MCM4-d2 and -d3 indicated that the 57 nucleotides from -44 to +12 were of primary importance for MCM4 promoter activity and its positive response to Rsv. The response was observed in pGL4-MCM4-d5-transfected cells, indicating that the sequence from -44 to -21 , containing the putative c-ETS binding sequence and GC-box, was the minimum Rsv responding core element both in HeLa S3 and HL-60 cells. To further examine the contribution of these cis-elements, point mutations were introduced in the Luc expression construct pGL4-MCM4-d7WT, containing 
125 CCTGCAGCCG CAGCAGGGAG CAACGCACAC CGGCTCCGGA GCCCGCCATG

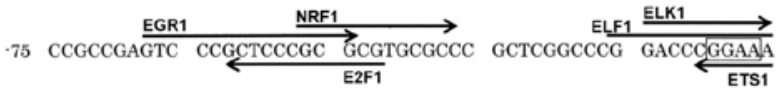

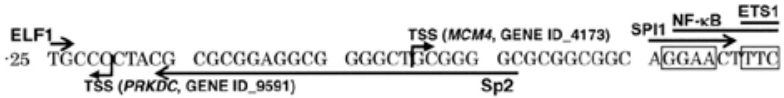

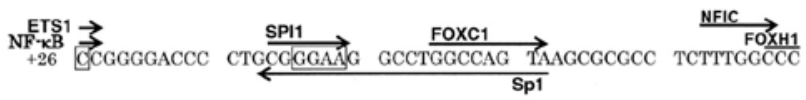

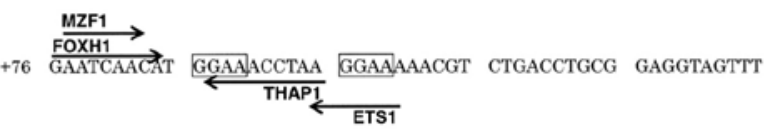

B
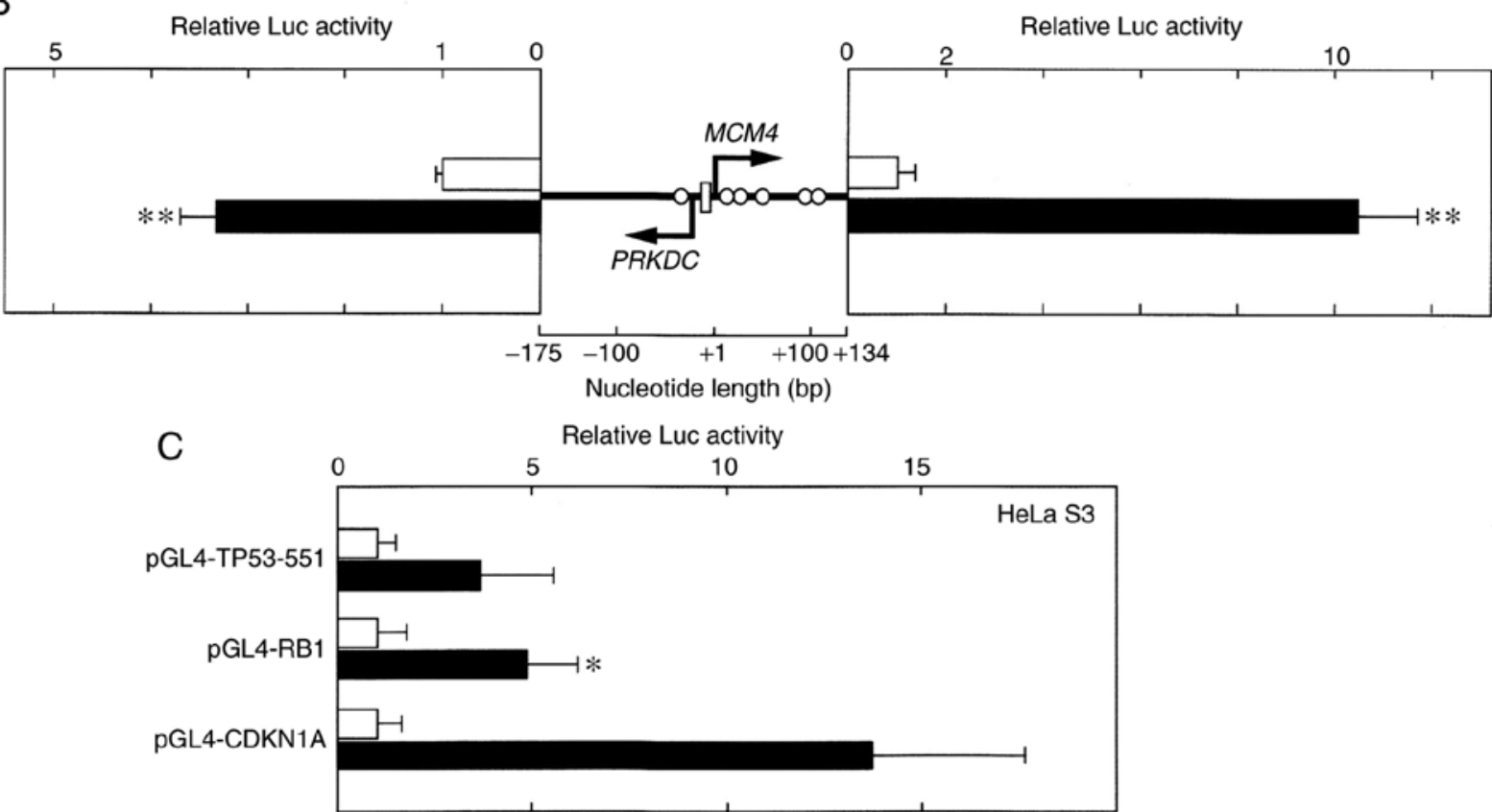

Figure 1. Characterization of the human MCM4/PRKDC bi-directional promoter region. (A) The nucleotide sequence of the 309-bp fragment that was obtained from PCR is presented. The most upstream 5' end of the human MCM4 (NM_005914.3 and NM_182746.2) and PRKDC (NM_001081640.1 and NM_006904.6) cDNAs are designated transcription start sites (TSSs). Putative transcription factor-binding sites (JASPAR database program, threshold $>90 \%$ ) are indicated by arrows. (B) The 309-bp fragment, which contained both TSSs of the MCM4 and the PRKDC genes, is schematically presented (center). Open circles and a rectangle represent GGAA (TTCC) motifs and a GC-box, respectively. The luciferase (Luc) reporter plasmids pGL4-PRKDC-309 (left) or pGL4-MCM4-309 (right) were transfected into HeLa S3 cells, which were treated with (closed columns) or without (open columns) Rsv (20 $\mu \mathrm{M}$ ) for $24 \mathrm{~h}$. Luc activities were normalized to that of the pGL4-PIF1-transfected cells. Histograms show relative Luc activities compared with that of the Rsv non-treated cells. (C) The Luc reporter plasmids pGL4-TP53-551, pGL4-RB1, and pGL4-CDKN1A were transfected into HeLa S3 cells, which were treated with or without Rsv $(20 \mu \mathrm{M})$ for $24 \mathrm{~h}$. Results show fold activation of the normalized Luc activities compared with that of Rsv-non-treated cells. (B and C) Results are presented as the means \pm SD from at least three independent experiments. Statistical analysis for the results between Rsv-treated and non-treated cells was performed with the Student's t-test. " $\mathrm{P}<0.05$. TSSs, transcription start sites; Rsv, trans-resveratrol. MCM4, minichromosome maintenance 4; PRKDC, protein kinase, DNA-activated, catalytic subunit.

the nucleotide from -44 to +2 , and a transient transfection experiment was carried out. Mutations on the c-ETS element and GC-box (in pGL4-MCM4-d7M1 and -d7M2, respectively) greatly reduced basal promoter activity and its response to Rsv (Fig. 3B). Cells that were transfected with pGL4-MCM4-d7MM, carrying double mutations on both the c-ETS and GC-box elements, also exhibited no apparent promoter activity or response to Rsv. Collectively, these results indicated that the MCM4 promoter was co-operatively regulated by the c-ETS element and GC-box to respond positively to Rsv in both the HeLa S3 and HL-60 cell lines.

Detection of proteins that bind to the Rsv response element in the MCM4 promoter. To identify proteins that interact with the Rsv response element, competition and supershift EMSAs were performed with HeLa S3 cell nuclear 


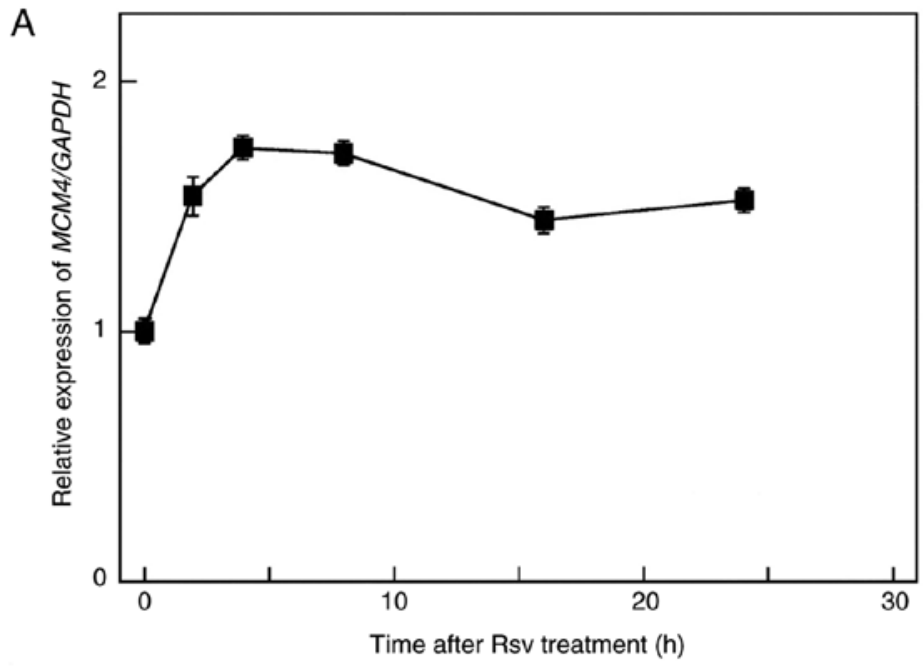

B

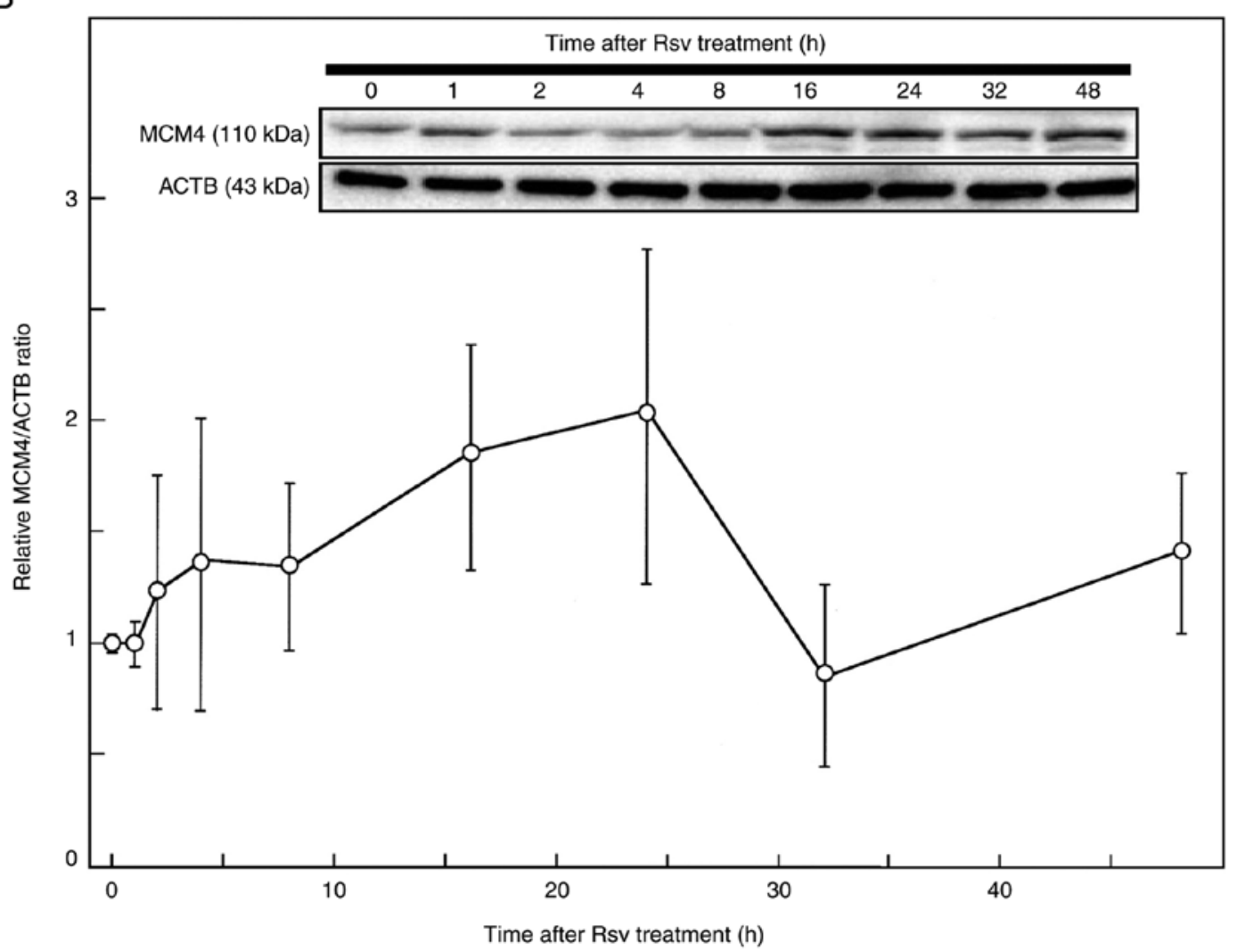

Figure 2. Effects of Rsv on MCM4 gene and protein expression. (A) The culture medium of HeLa S3 cells was changed to DMEM (containing 10\% FBS) with $20 \mu \mathrm{M}$ of Rsv. Cells were harvested after $0,2,4,8,16$, and $24 \mathrm{~h}$ of treatment. Total RNAs were extracted from cells, and synthesized cDNAs were subjected to real-time quantitative PCR with primer pairs to amplify MCM4 (upper panel) and GAPDH (lower panel) transcripts. The results revealed the relative $M C M 4 / G A P D H$ gene expression ratio compared with that of Rsv non-treated cells. Results are presented as the means \pm SD from at least three independent experiments. (B) HeLa S3 cells were collected after $0,1,2,4,8,16,24,32$, and $48 \mathrm{~h}$ of Rsv $(20 \mu \mathrm{M})$ treatment. The extracted proteins were separated by a $15 \%$ SDS-PAGE, and western blotting was performed with primary antibodies against MCM4 and ACTB ( $\beta$-actin) (upper and lower rows, respectively). The signal of each band was quantified, and the results revealed the relative MCM4/ACTB expression ratio compared with that of the non-treated control cells $(0 \mathrm{~h}$ treatment). Results are presented as the means \pm SD from three independent experiments. Rsv, trans-resveratrol; $M C M 4$, minichromosome maintenance 4 .

extracts. Incubation of the double-stranded DNA fragment, containing -44 to +2 of the MCM4 promoter, with Rsv-non-treated cell nuclear extracts (Fig. 4A, lane 3) gave rise to retarded bands, which were increased by the Rsv treatment (lane 2). The d7WT-protein complexes that were generated by incubation with Rsv-non-treated cell nuclear extract were reduced by the addition of non-labeled d7WT but not by d7M1, d7M2, and d7MM probes (Fig. 4A). This result indicated that formation of the d7WT-protein complex was dependent on the c-ETS binding sequence GGAA and Sp1-binding sequence GC-box (31). The addition of the anti-PU.1 antibody markedly decreased the formation of the d7WT-protein complexes -1 and -2 , whereas anti-ELK and anti-ETS1 antibodies did not (Fig. 4B, lanes 2-4). This result indicated that PU.1 is contained in the complexes -1 and -2 that bind to the Rsv response element of the 

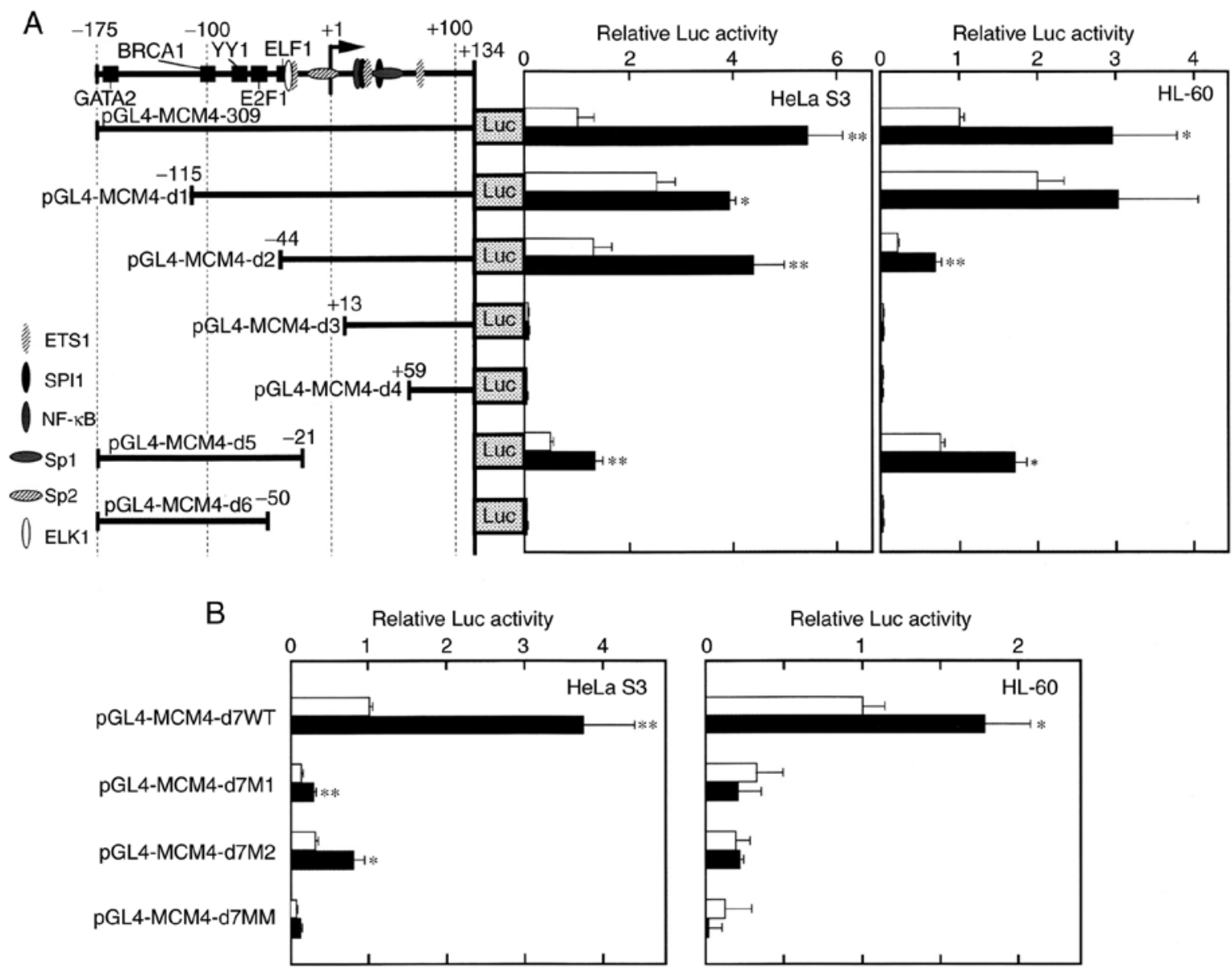

Figure 3. Effect of Rsv on human MCM4 promoter activity. (A) (Left panel) The 5' upstream end of the human MCM4 gene, which has been ligated upstream of the Luciferase gene of the pGL4.10[luc2], is presented. The 5' end of the cDNA is designated +1 . Transcription factor binding elements that were predicted by the JASPAR database program (threshold $>90 \%$ ) are schematically presented. (Right panels) Luciferase (Luc) reporter plasmids were transiently transfected into HeLa S3 or HL-60 cells and treated with (closed bars) or without (open bars) Rsv (20 $\mu \mathrm{M}$ ) for $24 \mathrm{~h}$. Luc activities were normalized to that of the pGL4-PIF1-transfected cells. Histograms revealed relative Luc activities of deletion construct-transfected cells compared with that of the pGL4-MCM4-309-transfected cells without Rsv treatment. (B) Mutation analysis on the 57-bp human MCM4 minimum promoter region. Nucleotide sequences that are contained in the Luc reporter plasmids pGL4-MCM4-d7WT, pGL4-MCM4-d7M1, pGL4-MCM4-d7M2, and pGL4-MCM4-d7MM are presented in Table II. Similar transfection experiments with HeLa S3 (left) and HL-60 (right) cells were carried out as described in A. Histograms revealed relative Luc activities of point mutation-introduced construct-transfected cells compared with that of the pGL4-MCM4-d7WT-transfected cells without Rsv treatment. (A and B) Results presented as the means \pm SD from three independent experiments. Statistical analysis was performed with the Student's t-test. ${ }^{*} \mathrm{P}<0.05$ and ${ }^{* *} \mathrm{P}<0.01$. Rsv, trans-resveratrol; MCM4, minichromosome maintenance 4.

MCM4 promoter. The JASPAR program also predicted that the Rsv-responsive sequence $(-44$ to +2$)$ contained the GC-box, indicating that Sp1 was essentially required for the Rsv response. The d7WT-protein complex was markedly reduced by the addition of anti-Sp1 or anti-STAT1 antibodies, indicating interactions of Sp1 and STAT1 with the d7WT probe (Fig. 4B, lane 6).

Next, protein amounts after Rsv treatment were analyzed by western blotting. As revealed in Fig. 5A, an increase of Sp1 and a decrease of PU.1 were observed. The Sp1/PU.1 ratio was markedly induced $24 \mathrm{~h}$ after the addition of Rsv to the culture medium (Fig. 5B).

\section{Discussion}

The present study revealed that treatment with Rsv $(20 \mu \mathrm{M})$ induced MCM4 gene and protein expression in HeLa S3 cells. Deletion and mutation analyses revealed that $\mathrm{c}-\mathrm{Ets}$ and GC-box elements co-operatively responded to Rsv.
Previously, ChIP (chromatin immunoprecipitation) analysis of the chicken Mcm4-Prkdc bi-directional promoter revealed that the c-Myb protein binds to that region (30). Mutated p53 affects the amount of MCM4 protein in breast cancer cell lines (32). At present, however, it has not been elucidated how human MCM4 gene expression is controlled. The duplicated GGAA (TTCC) motifs are frequently found in the promoter regions of genes encoding DNA repair and genome maintenance factors $(15,33)$. The duplicated GGAA motif in the human TP53 promoter is an essential element that confers positive response to Rsv in HeLa S3 cells (20). Although the duplicated GGAA (TTCC) in the 309-bp fragment of the human MCM4 promoter is not essential for a positive response to Rsv, it was completely abolished by introduction of mutations on the c-ETS recognition sequence (-31 to -26) and the GC-box (-10 to -3$)$. Similar results were observed in the human $H E L B$ promoter region (19). We have reported that the GC-box, which is a target binding sequence motif for $\mathrm{Sp} 1$, is commonly contained in the WRN and TERT promoter 
A

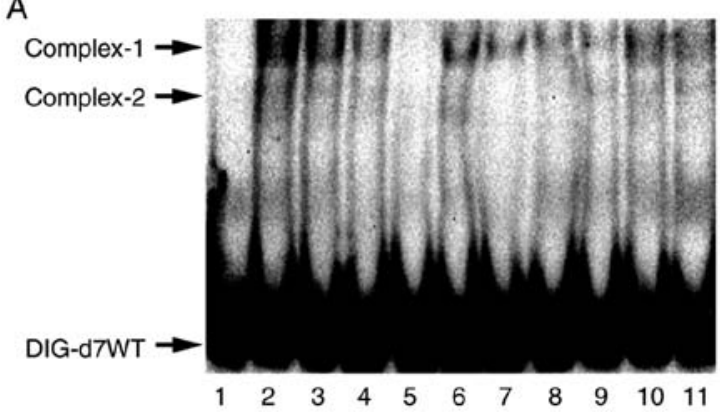

B

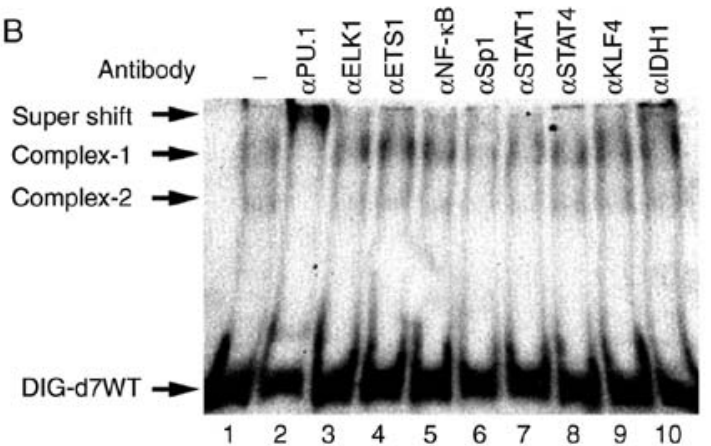

Figure 4. Sequence-specific DNA-protein complex formation at the Rsv-responding region of the MCM4 promoter. (A) Identification of protein-DNA complexes that specifically bind to the d7WT probe. The sequences of the double-stranded oligonucleotide probes for EMSA are presented in Table II. Nuclear extracts derived from HeLa S3 cells, which were either cultured with Rsv $(20 \mu \mathrm{M})$ containing DMEM for $24 \mathrm{~h}$ (lane 2) or mock stimulated (lanes 3 to 11 ), were subjected to EMSA with the 3 ' end DIG-labeled probe d7WT. The sequence-specific formations of the complexes were examined by competition assays with unlabeled specific d7WT (lanes 4 and 5), and d7M1 (lanes 6 and 7), d7M2 (lanes 8 and 9), and d7MM (lanes 10 and 11) double-stranded probes. The molar excess of unlabeled competitor was either 5-fold (lanes 4, 6, 8, and 10) or 10-fold (lanes 5, 7, 9, and 11). (B) Supershift EMSA analysis was performed with Rsv non-treated HeLa S3 extract and antibodies (1.0 $\mu$ l) targeting PU.1, Elk1, ETS1, NF-кB (p50), Sp1, STAT1, STAT4, KLF4, and IDH1 (lanes 2 to 10, respectively), which were included in the binding reaction. (A and B) Lane 1 represents a binding reaction without an antibody. Arrows indicate DIG-labeled d7WT probe, DNA-protein complexes, and a supershifted complex. Rsv, trans-resveratrol; EMSA, electrophoretic mobility shift assay; MCM4, minichromosome maintenance 4 .

regions $(21,23,25)$. The Rsv-responsive nucleotide sequence from -35 to -22 in the MCM4 promoter is 5 '-GACCCGGAA ATGCC-3' (Fig. 3B), which can be recognized by Ets family class IIa proteins, including EHF and ELF1-5 (34). In human cells, co-operative functioning of the ETS family and Sp1 has been reported in the PTGIR (35) and PARG (36) gene promoters. The duplicated GGAA (TTCC) motif and multiple GC-boxes are present in the 5' upstream end of the human TERT gene (21,33). Notably, mutations on the GGAA (TTCC) motifs or the creation of Ets binding elements in the TERT promoter are frequently found in human melanoma $(37,38)$. These observations suggest that cis-acting functions of the GGAA motifs and GC-boxes co-operatively regulate promoter activities of DNA replication/repair factor-encoding genes, including HELB, MCM4, PRKDC, and TERT, in response to biological stresses. Moreover, the present study indicated that both Sp1 and PU.1 are contained in the d7WT-protein complex, which was strengthened by Rsv treatment. PU.1 can regulate the differentiation and development of lymphoid cells $(39,40)$,
A
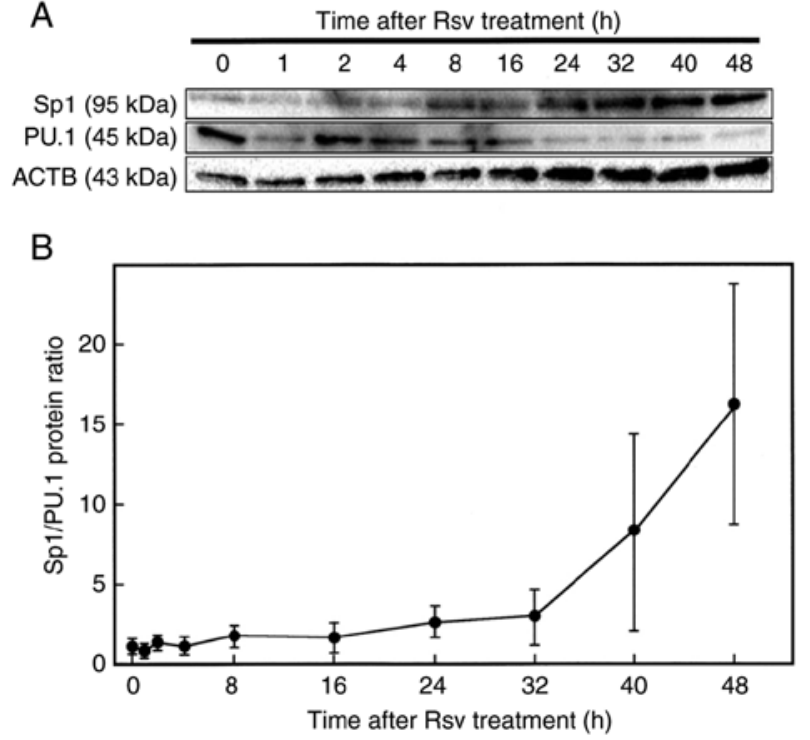

Figure 5. Amounts of Sp1 and PU.1 in HeLa S3 cells after Rsv treatment. (A) A similar experiment as described in Fig. 2B was carried out. After separation of proteins by a $15 \%$ SDS-PAGE, western blotting was performed with primary antibodies against Sp1, PU.1, and $\beta$-actin (ACTB) (upper, middle, and lower panels, respectively). (B) The signal of each band was quantified, and the result revealed the relative Sp1/PU.1 protein ratio. Results are presented as the means \pm SD from three independent experiments. Rsv, trans-resveratrol.

and it controls fibroblast polarization (41). The induction of PU.1 enforces differentiation of fibroblasts into a fibrotic phenotype. In the Rsv-treated HeLa S3 cells, the amount of PU.1 protein was gradually decreased. PU.1 has both stimulatory and suppressive functions on gene transcription (42). In the experimental settings of this study, PU.1 may have acted as a suppressor for MCM4 gene transcription.

The natural compound Rsv upregulated the expression of the TP53 and HELB genes and its encoded proteins in HeLa S3 cells $(19,20)$. The tumor suppressor p53 is a 'guardian of the genome' that induces cell cycle regulatory factor-encoding genes, which regulate cellular senescence, apoptosis, and autophagy, in response to DNA damage stresses (17). The human HELB $(H D H B)$ gene encodes a DNA replication-associated helicase (18). The dominant negative mutant HDHB protein, lacking ATPase/helicase activities, inhibited DNA synthesis when it was micro-injected into the nucleus of cells at the early $\mathrm{G}_{1}$ phase (18). A recent study indicated that the recruitment of HELB to sites of DNA double-strand breaks plays a role in the inhibition of DNA end resection (43). Moreover, the HELB protein has been revealed to interact with the DNA replication protein factor CDC45 (44). It should be noted that the MCM complex, whose structure has been recently revealed by cryo-electron microscopy (45), is associated with CDC45 and GINS $(12,46)$. The timing of the CMG complex formation at the origin of replication should be faithfully limited (47). The 5' upstream regions of the $R B 1$ and CDKN1A ( $p 21)$ genes $(22,48)$, carrying duplicated GGAA motifs, respond to Rsv in HeLa S3 cells. These results indicated that the expression of genes encoding p53, HELB, CDC45, MCM4, RB1, and CDKN1A need to be accurately regulated before entering the $\mathrm{S}$ phase. Additionally, the MCM4 gene has been revealed to 
be overexpressed in human cervical (49) and lung (50) cancer cells, suggesting that its expression should be appropriately controlled. In mice embryo, genomic instability, which was caused by a deficiency in MCM complex, triggered an inflammatory response (51). Given that interferon-stimulated genes are regulated by GGAA motifs (28), the transcription factors, including PU.1 and Sp1, that regulate MCM4 gene expression may simultaneously modulate immune responses.

The TP53 gene is inactivated by the human papillomavirus (HPV) E6 protein (52), and HL-60 cells have large homozygous deletion of the TP53 gene (53). The p53-deficient HL-60 cells were selected as well, to examine the effect of Rsv on the MCM4 promoter activity. The results revealed that the MCM4 promoter activation was evident in both cell lines, indicating that it basically was not dependent on the TP53 gene, whose mutations are very frequently found in various cancers.

Rsv has an effect on lengthening the life span of organisms $(54,55)$. Numerous clinical trials suggest that health-promoting responses, including reduction in the generation of reactive oxygen species and induction of insulin sensitivity, are induced by Rsv treatment (56). Further investigations are required to elucidate the mechanisms by which Rsv-induced signals regulateDNA replication/repair-associated gene expression.

\section{Acknowledgements}

The authors are grateful to Jun Arakawa, Yutaka Takihara, and Sakiko Kawahara for their excellent technical assistance. This study was performed under the permission of recombinant DNA experimental committee admission no. 1462 of Tokyo University of Science.

\section{Funding}

The present study was supported in part by JSPS KAKENHI grant no. 24510270 and a Research Fellowship from the Research Center for RNA Science, RIST, Tokyo University of Science.

\section{Availability of data and materials}

The datasets used and/or analyzed during the current study are available from the corresponding author on reasonable request.

\section{Authors' contributions}

MoA and MK constructed the Luc reporter plasmids. CK, MoA, $\mathrm{MK}$, and MT performed the experiments and analyzed the data (transfection assay, RT-PCR, western blotting, and EMSA). FU interpreted the data and wrote the manuscript. SIT collected and analyzed/interpreted the data. MaA interpreted the data and edited the manuscript. All authors have read and approved the final manuscript and agree to be accountable for all aspects of the research in ensuring that the accuracy or integrity of any part of the work are appropriately investigated and resolved.

\section{Ethics approval and consent to participate}

Not applicable.

\section{Patient consent for publication}

Not applicable.

\section{Competing interests}

The authors declare that they have no competing interests.

\section{References}

1. Mcintosh D and Blow JJ: Dormant replication origins. In: Cold Spring Harbor Perspectives in Biology 'DNA Replication'. Bell SD, Méchali M and DePamphilis M (eds). Cold Spring Harbor Laboratory Press, Woodbury, NY, pp33-42, 2013.

2. Tanaka S and Araki H: Helicase activation and establishment of replication forks at chromosomal origins of replication. In: Cold Spring Harbor Perspectives in Biology 'DNA Replication'. Bell SD, Méchali M and DePamphilis M (eds). Cold Spring Harbor Laboratory Press, Woodbury, NY, pp81-94, 2013.

3. Bell S and Kagni JM: Helicase loading at chromosomal origins of replication. In: Cold Spring Harbor Perspectives in Biology 'DNA Replication'. Bell SD, Méchali M and DePamphilis M (eds). Cold Spring Harbor Laboratory Press, Woodbury, NY, pp61-80, 2013.

4. Coster G and Diffley JFX: Bidirectional eukaryotic DNA replication is established by quasi-symmetrical helicase loading. Science 357: 314-318, 2017.

5. You Z, De Falco M, Kamada K, Pisani FM and Masai H: The mini-chromosome maintenance $(\mathrm{Mcm})$ complexes interact with DNA polymerase $\alpha$-primase and stimulate its ability to synthesize RNA primers. PLoS One 8: e72408, 2013.

6. Sheu Y, Kinney JB and Stillman B: Concerted activities of Mcm4, Sld3, and Dbf4 in control of origin activation and DNA replication fork progression. Genome Res 26: 315-330, 2016.

7. Shima N, Alcaraz A, Liachko I, Buske TR, Andrews CA, Munroe RJ, Hartford SA, Tye BK and Schimenti JC: A viable allele of Mcm4 causes chromosome instability and mammary adenocarcinomas in mice. Nat Genet 39: 93-98, 2007.

8. Tatsumi R and Ishimi Y: An MCM4 mutation detected in cancer cells affects MCM4/6/7 complex formation. J Biochem 161: 259-268, 2017.

9. Lee Y, Park T, Lee S and Lee H: Characterization of genetic aberrations in a single case of metastatic thymic adenocarcinoma. BMC Cancer 17: 330, 2017.

10. Zhai Y, Cheng E, Wu H, Li N, Yung PY, Gao N and Tye BK: Open-ringed structure of the $\mathrm{Cdt1}-\mathrm{Mcm} 2-7$ complex as a precursor of the MCM double hexamer. Nat Struct Mol Biol 24: 300-310, 2017.

11. Yuan Z, Riera A, Bai L, Sun J, Nandi S, Spanos C, Chen ZA, Barbon M, Rappsilber J, Stillman B, et al: Structural basis of Mcm 2-7 replicative helicase loading by ORC-Cdc6 and Cdt1. Nat Struct Mol Biol 24: 316-326, 2017.

12. Wei L and Zhao X: A new MCM modification cycle regulates DNA replication initiation. Nat Struct Mol Biol 23: 209-218, 2016.

13. Moritani M and Ishimi Y: Inhibition of DNA binding of MCM2-7 complex by phosphorylation with cyclin-dependent kinases. J Biochem 154: 363-372, 2013.

14. Sheu YJ, Kinney JB, Lengronne A, Pasero P and Stillman B: Domain within the helicase subunit Mcm4 integrates multiple kinase signals to control DNA replication initiation and fork progression. Proc Natl Acad Sci USA 111: E1899-E1908, 2014.

15. Uchiumi F, Larsen S and Tanuma S: Biological systems that control transcription of DNA repair and telomere maintenance-associated genes. In: New Research in Directions in DNA Repair. Chen C (ed). InTech Open, London, pp309-325, 2013.

16. Uchiumi F, Arakawa J, Takihara Y, Akui M, Ishibashi S and Tanuma S: The effect of trans-resveratrol on the expression of the human DNA-repair associated genes. Int Mol Med 3: 783-792, 2016.

17. Zilfou JT and Lowe SW: Tumor suppressive functions of p53. In: Cold Spring Harbor Perspectives in Biology. Levine AJ and Lane D (eds). Cold Spring Harbor Laboratory Press, Woodbury, NY, pp1-12, 2009. 
18. Taneja P, Gu J, Peng R, Carrick R, Uchiumi F, Ott RD, Gustafson E, Podust VN and Fanning E: A dominant-negative mutant of human DNA helicase B blocks the onset of chromosomal DNA replication. J Biol Chem 277: 40853-40861, 2002.

19. Uchiumi F, Arakawa J, Iwakoshi K, Ishibashi S and Tanuma S: Characterization of the 5'-flanking region of the human DNA helicase B (HELB) gene and its response to trans-Resveratrol. Sci Rep 6: 24510, 2016.

20. Uchiumi F, Shoji K, Sasaki Y, Sasaki M, Sasaki Y, Oyama T, Sugisawa S and Tanuma S: Characterization of the 5'-flanking region of the human TP53 gene and its response to the natural compound, Resveratrol. J Biochem 159: 437-447, 2016.

21. Uchiumi F, Higami Y and Tanuma S: Regulations of telomerase activity and $W R N$ gene expression. In: Telomerase: Composition, Functions and Clinical Implications. Gagnon AN (ed). Nova Science Publishers Inc, Hauppauge, NY, pp95-103, 2010.

22. Uchiumi F, Watanabe $T$ and Tanuma S: Characterization of various promoter regions of the human DNA helicase-encoding genes and identification of duplicated ets (GGAA) motifs as an essential transcription regulatory element. Exp Cell Res 316: 1523-1534, 2010

23. Zhou B, Ikejima T, Watanabe T, Iwakoshi K, Idei Y, Tanuma S and Uchiumi F: The effect of 2-deoxy-D-glucose on Werner syndrome RecQ helicase gene. FEBS Lett 583: 1331-1336, 2009.

24. Uchiumi F, Oyama T, Ozaki K and Tanuma S: Characterization of 5'-flanking regions of various human telomere maintenance factor-encoding genes. In: DNA Repair. Kruman I (ed). InTech Open, London, pp585-596, 2011.

25. Uchiumi F, Watanabe T, Hasegawa S, Hoshi T, Higami Y and Tanuma S: The effect of resveratrol on the Werner Syndrome RecQ helicase gene and telomerase activity. Curr Aging Sci 4: $1-7,2011$.

26. Livak KJ and Schmittgen TD: Analysis of relative gene expression data using real-time quantitative PCR and the 2(-Delta Delta C(T)) method. Methods 25: 402-408, 2001

27. Uchiumi F, Larsen S and Tanuma S: Application of DEAE-dextran to an efficient gene transfer system. In: Dextran: Chemical Structure, Application and Potential Side Effects. Figgs GP (ed). Nova Science Publishers Inc., Hauppauge, NY, pp143-156, 2014.

28. Larsen S, Kawamoto S, Tanuma $S$ and Uchiumi F: The hematopoietic regulator, ELF-1, enhances the transcriptional response to Interferon- $\beta$ of the OAS1 anti-viral gene. Sci Rep 5: 17497, 2015

29. Takihara Y, Sudo D, Arakawa J, Takahashi M, Sato A, Tanuma S and Uchiumi F: Nicotinamide adenine dinucleotide $\left(\mathrm{NAD}^{+}\right)$and cell aging. In: New Research on Cell Aging and Death. Strakoš R and Lorens B (eds). Nova Science Publishers Inc., Hauppauge, NY, pp131-158, 2018.

30. Gundelach H, Braas D and Klempnauer KH: The promoter regions of the Myb-regulated Adora2B and $\mathrm{Mcm} 4$ genes co-localize with origins of DNA replication. BMC Mol Biol 8: $75,2007$.

31. Wieratra I: Sp1: Emerging roles-Beyond constitutive activation of TATA-less housekeeping genes. Biochem Biophys Res Commun 372: 1-13, 2008.

32. Polotskaia A, Xiao G, Reynoso K, Martin C, Qiu WG Hendrickson RC and Bargonetti J: Proteome-wide analysis of mutant p53 targets in breast cancer identifies new levels of gain-of-function that influence PARP, PCNA, and MCM4. Proc Natl Acad Sci USA 112: E1220-E1229, 2015.

33. Uchiumi F, Larsen S and Tanuma S: Transcriptional regulation of the human genes that encode DNA repair- and mitochondrial function-associated proteins. In: Advances in DNA Repair. Chen C (ed). InTech Open, London, pp129-167, 2015.

34. Wei GH, Badis G, Berger MF, Kivioja T, Palin K, Enge M, Bonke M, Jolma A, Varjosalo M, Gehrke AR, et al: Genome-wide analysis of ETS-family DNA-binding in vitro and in vivo. EMBO J 29: 2147-2160, 2010

35. Turner EC and Kinsella BT: Transcriptional regulation of the human prostacyclin receptor gene is dependent on Sp1, PU.1 and Oct-1 in megakaryocytes and endothelial cells. J Mol Biol 386 579-597, 2009.
36. Molloy-Simard V, St-Laurent JF, Vigneault F, Gaudreault M, Dargis N, Guérin MC, Leclerc S, Morcos M, Black D, Molgat Y, et al: Altered expression of the poly(ADP-ribosyl) ation enzymes in uveal melanoma and regulation of PARG gene expression by the transcription factor ERM. Invest Ophthalmol Vis Sci 53: 6219-6231, 2012.

37. Huang FW, Hodis E, Xu MJ, Kryukov GV, Chin L and Garraway LA: Highly recurrent TERT promoter mutations in human melanoma. Science 339: 957-959, 2013

38. Horn S, Figl A, Rachakonda PS, Fischer C, Sucker A, Gast A, Kadel S, Moll I, Nagore E, Hemminki K, et al: TERT promoter mutations in familial and sporadic melanoma. Science 339: 959-961, 2013.

39. Carotta S, Wu L and Nutt SL: Surprising new roles for PU.1 in the adaptive immune response. Immunol Rev 238: 63-75, 2010.

40. Rothenberg EV, Hosokawa H and Ungerbäck J: Mechanisms of action of hematopoietic transcription factor PU.1 in initiation of T-cell development. Front Immunol 10: 228, 2019.

41. Wohlfahrt T, Rauber S, Uebe S, Luber M, Soare A, Ekici A, Weber S, Matei AE, Chen CW, Maier C, et al: PU.1 controls fibroblast polarization and tissue fibrosis. Nature 566: 344-349, 2019.

42. Hosokawa H, Ungerbäck J, Wang X, Matsumoto M,Nakayama KI, Cohen SM, Tanaka T and Rothenberg EV: Transcription factor PU.1 represses and activates gene expression in early T cells by redirecting partner transcription factor binding. Immunity 48: 1119-1134 e7, 2018

43. Tkáč J, Xu G, Adhikary H, Young JTF, Gallo D, Escribano-Díaz C, Krietsch J, Orthwein A, Munro M, Sol W, et al: HELB is a feedback inhibitor of DNA end resection. Mol Cell 61: 405-418, 2016.

44. Gerhardt J, Guler GD and Fanning E: Human DNA helicase B interacts with the replication initiation protein Cdc45 and facilitates Cdc45 binding onto chromatin. Exp Cell Res 334: 283-293, 2015.

45. Miller TCR, Locke J, Greiwe JF, Diffley JFX and Costa A: Mechanism of head-to-head MCM double-hexamer formation revealed by cryo-EM. Nature 575: 704-710, 2019.

46. Araki H: Molecular mechanisms of DNA replication. In: DNA Replication, Recombination, and Repair. Hanaoka F and Sugasawa K (eds). Springer Japan, Tokyo, pp3-22, 2016.

47. Hayano M, Matsumoto S and Masai H: DNA replication timing: Temporal and spatial regulation of eukaryotic DNA replication. In: DNA Replication, Recombination, and Repair. Hanaoka F and Sugasawa K (eds). Springer Japan, Tokyo, pp53-69, 2016

48. Deléhouzée S, Yoshioka T, Sawa C, Sawada J, Ito T, Omori M, Wada T, Yamaguchi Y, Kabe Y and Handa H: GABP, HCF-1 and $\mathrm{YY} 1$ are involved in $\mathrm{Rb}$ gene expression during myogenesis. Genes Cells 10: 717-731, 2005.

49. Cheng J, Lu X, Wang J, Zhang H, Duan P and Li C: Interactome analysis of gene expression profiles of cervical cancer reveals dysregulated mitotic gene clusters. Am J Transl Res 9: 3048-3059, 2017.

50. Yi J, Wei X, Li X, Wan L, Dong J and Wang R: A genome-wide comprehensive analysis of alterations in driver genes in non-small-cell lung cancer. Anticancer Drugs 29: 10-18, 2018.

51. McNairn AJ, Chuang CH, Bloom JC, Wallace MD and Schimenti JC: Female-biased embryonic death from inflammation induced by genomic instability. Nature 567: 105-108, 2019.

52. Kajitani K. Honda K, Terada H, Yasui T, Sumi T, Koyama M and Ishiko O: Human papillomavirus E6 knockdown restores adenovirus mediated-estrogen response element linked p53 gene transfer in HeLa cells. Asian Pac J Cancer Prev 16: 8239-8245, 2015.

53. Wolf D and Rotter V: Major deletions in the gene encoding the p53 tumor antigen cause lack of p53 expression in HL-60 cells. Proc Natl Acad Sci USA 82: 790-794, 1985.

54. Stefani M, Markus MA, Lin RC, Pinese M, Dawes IW and Morris BJ: The effect of resveratrol on a cell model of human aging. Ann NY Acad Sci 1114: 407-418, 2007.

55. Kaeberlein M: Resveratrol and rapamycin: Are they anti-aging drugs? Bioessays 32: 96-99, 2010.

56. Vang O: What is new for resveratrol? Is a new set of recommendations necessary? Ann NY Acad Sci 1290: 1-11, 2013. 